\title{
Research and Evaluation of Heavy Metal Pollution of Contaminated Site
}

\author{
Jiong Jiang \\ Shaanxi Provincial Land Engineering Construction Group Co., LTD, 710075, xi'an, Shaanxi, China
}

\begin{abstract}
This paper made the research on the heavy metal pollution situations in three areas of contaminated sites in Weinan city, including reactor, pollution source and administrative area. The results show that the contaminated sites are polluted at different levels, mainly $\mathrm{Hg}$ and As. The evaluation results of nemerow indexes demonstrate that the comprehensive pollution index of soil in reactor area is polluted seriously, the comprehensive pollution index of soil in pollution source area belongs to mild pollution and middle pollution and the comprehensive pollution index of soil in the administrative area belongs to clean pollution. The potential ecological risk of polluted site was evaluated by ecological hazard index method. The results show that the total potential ecological harm of soil in reactor belongs to strong grade. The potential ecological harm of $\mathrm{Hg}$ is strong, the potential ecological harm of Cd belongs to the medium level, As of $80 \%$ point belongs to the strong level, and As of $20 \%$ of the points belongs to the middle level. The potential ecological hazards of $\mathrm{Hg}$ and $\mathrm{Cd}$ are moderate. The potential ecological risk of $\mathrm{Hg}$ is strong, the potential ecological risk of $\mathrm{Cd}$ belongs to the middle level and the rest heavy metals are in the safety range. Moreover, the total potential ecological harm of soil is in the safety margin.
\end{abstract}

\section{Introduction}

Soil is the material base for human survival. Soil pollution not only affects and changes the ecological function of soil seriously, but also endangers the quality of agricultural products, threatens human health as well as sustainable social and economic development [1-3]. In recent years, the soil pollution events occur frequently and the prevention and treatment of soil pollution becomes the hot spot in the domain of environmental research at home and abroad [4-5]. With the same time, as the industrialization and urbanization develop, the large number of old factories migrate to the outside of the urban area and the problems of soil pollution left over from the relocation have attracted more and more attention [6]. Presently, the research on soil pollutants mainly focuses on pollution source investigation, pollution assessment, potential ecological risk assessment, pollution impact on human health and pollution remediation [7-8]. The assessment and remediation of soil pollution become a hot research topic [9-10].

Taking the waste industrial pollution site in Shaanxi Province as the investigation object, this paper investigated the pollution and distribution of heavy metals in the polluted area and evaluated the potential ecological health risks, which provided the basis for the later repair of the area.

\section{Materials and methods}

\subsection{Background of the study area}

Located in the east of Weinan city, the polluted area was originally the location of a state-owned chemical enterprise, which was close to drinking water sources and beach areas, such as Weihe. The project planning is wetland park and residential area, whose environment sensitive target is more concentrated and type is diverse. During the preliminary investigation, it is found that the soil texture of the plot is silt loam, which is dry and slightly pungent. Based on the development history of this area and the production of chemical plants, it is preliminarily judged that there is heavy metal pollution in the polluted area.

\subsection{Sample collection and treatment}

Before collecting the sample, the survey of the abandoned industrial area and surrounding area was carried out, which determined that the reactor, sewage discharge port and office area in the abandoned industrial area were the key sampling areas. The samples were collected as many as possible in each area and evenly mixed. The Weight of each sample was $1 \mathrm{~kg}$ and 11 samples were collected. After the collections, the samples were sent to the laboratory in 
time, stored in the area with shade, ventilation, light avoidance, no pollution, natural air drying. Therefore, the samples are suitable for crushing, screening, shrinkage.

To prevent cross contamination in sample testing, glassware and digestion cans were soaked in $5 \% \mathrm{HNO}_{3}$ for 24 hours before use. Then after they were washed and dried [11], they were pretreated by hydrochloric acid - nitric acid - hydrofluoric acid - perchloric acid total decomposition method.

\subsection{Evaluation standard and methods}

Since the local block will be used as the construction land in the planning, the screening value of the first type of land in the Soil Pollution Risk Management and Control Standard of the Soil Environmental Quality Construction Land (GB36600-2018) is adopted as the evaluation standard.

The pollution of $\mathrm{Pb}, \mathrm{Cd}, \mathrm{Zn}, \mathrm{As}$ and $\mathrm{Hg}$ in the soil of the sampling point was evaluated by single factor and internal plum pollution index method. The single factor polluted index method is the widely used environmental pollution assessment method at home and abroad. Though this method can only reflect the pollution degree of single pollutant and can not comprehensively reflect the status of soil heavy metal pollution, it can be used as the basis of comprehensive evaluation of soil heavy metal pollution. The formula (1) is shown as follows:

$$
P_{i}=\frac{C_{i}}{S_{i}}
$$

Where $P_{i}$ is the single factor evaluation index of the heavy metal elements; $C_{i}$ is the measured value of the soil pollutant; $S_{i}$ is the standard limits for soil pollutants.

The greater the single factor index, the higher level of the contamination of the single heavy metal. The classification standard of single pollution degree of soil is shown as table 1 .

Nemerow pollution index method not only reflects the comprehensive pollution condition of each pollutant to the environment, but also highlights the influence of the highest concentration of the pollutants. Its calculation formula is as follows:

$$
P_{\text {composite }}=\sqrt{\frac{\left(\frac{1}{n} \sum_{\mathrm{i}=1}^{n} P_{i}\right)^{2}+\mathrm{P}_{i \max }^{2}}{2}}
$$

Where $\frac{1}{n} \sum_{\mathrm{i}=1}^{n} P_{i}$ is the average value of each pollutant index, $P_{i \max }$ is maximum pollutant index and $\mathrm{n}$ is the number of evaluated pollutants. The classification standard of soil pollution by Nemero pollution index method is shown in Table 2.

Table 1 Classification standard of single pollution degree of soil

\begin{tabular}{cc}
\hline pollution index & Degree of soil pollution \\
\hline$P_{\mathrm{i}} \leq 1.0$ & Uncontaminated \\
\hline $1.0<P_{\mathrm{i}} \leq 2.0$ & Mild pollution \\
\hline $2.0<P_{\mathrm{i}} \leq 3.0$ & Moderately polluted \\
\hline$P_{\mathrm{i}}>3.0$ & Severe pollution \\
\hline
\end{tabular}

Table 2 Grading standard for comprehensive pollution degree of soil

\begin{tabular}{cccc}
\hline $\begin{array}{c}\text { Comprehensive } \\
\text { pollution level }\end{array}$ & $\begin{array}{c}\text { Comprehensive } \\
\text { pollution index }\end{array}$ & Degree of pollution & Pollution level \\
\hline 1 & $P_{\text {composite }} \leq 0.7$ & Security Level & clean \\
\hline 2 & $0.7<P_{\text {composite }} \leq 1.0$ & Warning line & Still clean \\
\hline 3 & $1.0<P_{\text {composite }} \leq 2.0$ & Mild pollution & Contaminants slightly exceed the standard \\
\hline 4 & $2.0<P_{\text {composite }} \leq 3.0$ & Moderately polluted & Significant pollution \\
\hline 5 & $P_{\text {composite }}>3.0$ & Severe pollution & serious pollution \\
\hline
\end{tabular}

\section{Results and discussions}

\subsection{Analysis of heavy metal content in soil}

The results of heavy metal content in polluted site are shown in Table 3, and the background value of heavy metal content in soil in Guanzhong area is shown in Table 4. From the table, it is seen that the contents of $\mathrm{Cu}$ and $\mathrm{Pb}$ are not different from the background concentration of soil mass in Guanzhong area. Except $\mathrm{Hg}$ and As, the contents of the other four heavy metals are much lower than the screening values of the first type of land in the Soil Environmental Quality Risk Control Standard for Soil Contamination of Development land. Specifically, four points of $\mathrm{Hg}$ in the sample exceed the standard value and the highest concentration exceeds the standard 1.09 times. Six points of As exceed the standard value and the highest concentration exceeds the standard 123.3 times. At the same time, the exceeding point is mainly located at the reactor area. Therefore, it is seen that the heavy metal $\mathrm{Hg}$ and As pollution mainly exist in the contaminated site and they are concentrated in the reactor area. 
Table 3 Heavy metal content in soil

\begin{tabular}{|c|c|c|c|c|c|c|c|}
\hline \multirow{2}{*}{ Sample serial number } & \multirow{2}{*}{ Sampling area } & \multicolumn{6}{|c|}{ Heavy metal content $(\mathrm{mg} / \mathrm{kg})$} \\
\hline & & $\mathrm{Ni}$ & $\mathrm{Cd}$ & $\mathrm{Cu}$ & $\mathrm{Pb}$ & $\mathrm{Hg}$ & As \\
\hline 1 & \multirow{5}{*}{ reactor } & 64.3 & 0.37 & 33.20 & 26.30 & 8.20 & 106.3 \\
\hline 2 & & 49.8 & 0.41 & 29.70 & 42.40 & 7.30 & 100.4 \\
\hline 3 & & 61.6 & 0.38 & 32.60 & 34.60 & 8.30 & 119.2 \\
\hline 4 & & 58.4 & 0.33 & 27.90 & 41.10 & 8.20 & 105.3 \\
\hline 5 & & 60.8 & 0.37 & 29.30 & 38.90 & 8.40 & 113.7 \\
\hline 6 & \multirow{3}{*}{ Sewage outlet } & 58.4 & 0.37 & 37.90 & 38.50 & 5.70 & 13.2 \\
\hline 7 & & 61.2 & 0.40 & 38.50 & 42.40 & 6.50 & 20.5 \\
\hline 8 & & 60.7 & 0.32 & 28.70 & 33.90 & 5.10 & 15.7 \\
\hline 9 & \multirow{3}{*}{ Office area } & 36.5 & 0.21 & 27.60 & 13.40 & 0.09 & 7.8 \\
\hline 10 & & 44.7 & 0.19 & 30.20 & 18.10 & 0.16 & 6.2 \\
\hline 11 & & 33.2 & 0.26 & 27.10 & 11.60 & 0.11 & 9.4 \\
\hline
\end{tabular}

Table 4 Heavy metal content in soil of Guanzhong area

\begin{tabular}{ccccccc}
\hline Polluted element & $\mathrm{Ni}$ & $\mathrm{Cd}$ & $\mathrm{Cu}$ & $\mathrm{Pb}$ & $\mathrm{Hg}$ & $\mathrm{As}$ \\
\hline Background values $(\mathrm{mg} / \mathrm{kg})$ & 33.13 & 0.184 & 26.7 & 24.8 & 0.084 & 13.1 \\
\hline Filter value $(\mathrm{mg} / \mathrm{kg})$ & 150 & 20 & 2000 & 400 & 8 & 20 \\
\hline
\end{tabular}

\subsection{Evaluation of heavy metal pollution in soil}

Based on the measured results of heavy metal content in polluted site 3 , formula 1 and formula 2 , the pollution indexes of heavy metal were calculated (as shown in Table 5). From Table 5, it is found that the single factor evaluation index of $\mathrm{Ni}, \mathrm{Cd}, \mathrm{Cu}$ and $\mathrm{Pb}$ in polluted site is less than 1, which is in the unpolluted state. The single factor evaluation index of $\mathrm{Hg}$ at four points is more than 1 , all of which are located at the reactor. Therefore, the soil at the reactor is in the state of mild pollution. The single factor evaluation index of $\mathrm{Hg}$ in sewage outlet area and office area is less than 1, which belongs to the unpolluted level. The single factor evaluation indexes of As at the five sampling points at the reactor are more than 3, which belongs to the severe pollution level. In 3 sampling points at the sewage outlet, only one point has a single factor evaluation index, which is slightly more than 1. The soil at the sewage outlet is between unpolluted and slightly polluted level. The single factor evaluation index of As in office area is less than 1, which is in the unpolluted level.

According to the Nemero pollution index method, the comprehensive pollution indexes of 11 points were calculated. Comprehensive pollution index of soil at reactor $P_{\text {composite }}$ is greater than 3 , which belongs to the serious pollution level. The reason why the comprehensive pollution index of the soil at the reactor is large is that the concentration of As in the soil is much higher than that of the standard value. Therefore, to reduce the concentration of As in the soil, it should focus on the repair of the As in the contaminated site. The comprehensive pollution indexes of soil at the sewage outlet are in the range of 1.90 2.39, which belongs to the light pollution and middle pollution level. At the same time, $\mathrm{Hg}$ and As should be repaired in order to reduce the concentration of these two heavy metals. The comprehensive pollution indexes of soil in office area are in the range of $0.7 \sim 0.76$, which belongs to the clean level. Therefore, the monitoring of the soil there should be strengthened.

Table 5 Soil heavy metal pollution index

\begin{tabular}{|c|c|c|c|c|c|c|c|c|}
\hline \multirow{2}{*}{$\begin{array}{l}\text { Sample serial } \\
\text { number }\end{array}$} & \multirow{2}{*}{ Sampling area } & \multicolumn{6}{|c|}{ Single factor evaluation index $P_{i}$} & \multirow{2}{*}{$\begin{array}{l}\text { Comprehensive pollution } \\
\text { index } P_{\text {composite }}\end{array}$} \\
\hline & & $\mathrm{Ni}$ & $\mathrm{Cd}$ & $\mathrm{Cu}$ & $\mathrm{Pb}$ & $\mathrm{Hg}$ & As & \\
\hline 1 & \multirow{5}{*}{ reactor } & 0.43 & 0.02 & 0.02 & 0.07 & 1.03 & 5.32 & 6.87 \\
\hline 2 & & 0.33 & 0.02 & 0.01 & 0.11 & 0.91 & 5.02 & 6.41 \\
\hline 3 & & 0.41 & 0.02 & 0.02 & 0.09 & 1.04 & 5.96 & 7.53 \\
\hline 4 & & 0.39 & 0.02 & 0.01 & 0.10 & 1.03 & 5.27 & 6.81 \\
\hline 5 & & 0.41 & 0.02 & 0.01 & 0.10 & 1.05 & 5.69 & 7.27 \\
\hline 6 & \multirow{3}{*}{ Sewage outlet } & 0.39 & 0.02 & 0.02 & 0.10 & 0.71 & 0.66 & 1.90 \\
\hline 7 & & 0.41 & 0.02 & 0.02 & 0.11 & 0.81 & 1.03 & 2.39 \\
\hline 8 & & 0.40 & 0.02 & 0.01 & 0.08 & 0.64 & 0.79 & 1.94 \\
\hline 9 & \multirow{3}{*}{ Office area } & 0.24 & 0.01 & 0.01 & 0.03 & 0.01 & 0.39 & 0.70 \\
\hline 10 & & 0.30 & 0.01 & 0.02 & 0.05 & 0.02 & 0.31 & 0.70 \\
\hline 11 & & 0.22 & 0.01 & 0.01 & 0.03 & 0.01 & 0.47 & 0.76 \\
\hline
\end{tabular}




\subsection{Ecological risk assessment}

The potential ecological hazard index method was proposed by the Swedish scientist Hakanson and is a widely used method for evaluating the degree of heavy metal pollution. It is comprehensively evaluated from the environmental, ecological and toxicological characteristics of heavy metals. The potential ecological hazard classification is shown in Table 6.

The calculation of the comprehensive potential ecological risk hazard index (RI) of many heavy metals in contaminated sites is shown in formula (3) (5) [12].

$$
\begin{aligned}
C_{\mathrm{r}}^{i} & =\frac{C_{\text {practical testing }}^{i}}{C_{n}^{i}} \\
E_{r}^{i} & =T_{r}^{i} \times C_{r}^{i} \\
R I & =\sum_{i=1}^{n} E_{r}^{i}
\end{aligned}
$$

Where $C_{\text {practical testing }}^{i}$ is the actual measurement of heavy metals $i ; C_{n}^{i}$ is the reference ratio of heavy metal $i$. In general, the local background value was taken as the reference value and the soil in Guanzhong area was selected as the background value in this paper. $T_{r}^{i}$ is the toxicity response coefficient of heavy metal $i$. By referring Hakanson value [13],
$\mathrm{Ni}=\mathrm{Cu}=\mathrm{Pb}=5, \mathrm{Cd}=30, \mathrm{Hg}=40, \quad \mathrm{As}=10 ; \quad E_{r}^{i}$ is potential ecological hazard index of heavy metal $i$.

By formulas (3) (5) and Table $3 \sim 4$, the potential ecological hazard indexes of single heavy metal and the total potential ecological hazard index of heavy metal were obtained, as shown in Table 7.

From Table 7, it is seen that the total potential ecological hazard indexes of reactors and sewage outlets in the contaminated plot is high. The value of eight sampling points in these two places is more than 2600, which is far more than 600 . The ecological risk level belongs to the strong level because the potential ecological hazard index of $\mathrm{Hg}$ is superior to the standard value and the potential ecological hazard index of the other five heavy metals. Therefore, the $\mathrm{Hg}$ in these two soil areas have the greatest potential harm to human body. However, the total potential ecological hazard index in the office area is low, and the potential ecological harm belongs to the slight level. Additionally, the potential ecological hazard indexes of $\mathrm{Cd}$ in the soil of reactor and sewage outlet are medium, which has potential harm to human body. Only the potential hazard grade of As at 4 points at the reactor is at a strong level and the potential hazard level at one point is at the medium level. The potential ecological hazard index of soil in sewage outlet and office area is less than 40, and the ecological risk belongs to a slight level. The potential ecological hazard indexes of $\mathrm{Ni}, \mathrm{Cu}$ and $\mathrm{Pb}$ in three areas are lower and its potential ecological harm belongs to the lowest level. In addition, its risk is lower and it belongs to the safety range.

Table 6 Classification of potential ecological hazards

\begin{tabular}{|c|c|c|c|c|c|c|c|c|}
\hline \multirow{2}{*}{$\begin{array}{l}\text { Sample serial } \\
\text { number }\end{array}$} & \multirow{2}{*}{$\begin{array}{l}\text { Sampling } \\
\text { area }\end{array}$} & \multicolumn{6}{|c|}{ Single heavy metal potential ecological hazard index $E_{r}^{i}$} & \multirow{2}{*}{$\begin{array}{l}\text { Total potential ecological } \\
\text { hazard index } R I\end{array}$} \\
\hline & & $\mathrm{Ni}$ & $\mathrm{Cd}$ & $\mathrm{Cu}$ & $\mathrm{Pb}$ & $\mathrm{Hg}$ & As & \\
\hline 1 & \multirow{5}{*}{ reactor } & 9.70 & 60.33 & 6.22 & 5.30 & 4100.00 & 81.15 & 4262.69 \\
\hline 2 & & 7.52 & 66.85 & 5.56 & 8.55 & 3650.00 & 76.64 & 3815.12 \\
\hline 3 & & 9.30 & 61.96 & 6.10 & 6.98 & 4150.00 & 90.99 & 4325.33 \\
\hline 4 & & 8.81 & 53.80 & 5.22 & 8.29 & 4100.00 & 80.38 & 4256.51 \\
\hline 5 & & 9.18 & 60.33 & 5.49 & 7.84 & 4200.00 & 86.79 & 4369.63 \\
\hline 6 & \multirow{3}{*}{$\begin{array}{c}\text { Sewage } \\
\text { outlet }\end{array}$} & 8.81 & 60.33 & 7.10 & 7.76 & 2850.00 & 10.08 & 2944.08 \\
\hline 7 & & 9.24 & 65.22 & 7.21 & 8.55 & 3250.00 & 15.65 & 3355.86 \\
\hline 8 & & 9.16 & 52.17 & 5.37 & 6.83 & 2550.00 & 11.98 & 2635.53 \\
\hline 9 & \multirow{3}{*}{$\begin{array}{l}\text { Office } \\
\text { area }\end{array}$} & 5.51 & 34.24 & 5.17 & 2.70 & 42.50 & 5.95 & 96.07 \\
\hline 10 & & 6.75 & 30.98 & 5.66 & 3.65 & 80.00 & 4.73 & 131.76 \\
\hline 11 & & 5.01 & 42.39 & 5.07 & 2.34 & 55.00 & 7.18 & 116.99 \\
\hline
\end{tabular}

\begin{tabular}{cccccc}
\hline Ecological risk level & slight & medium & Slightly strong & Strong & Extremely strong \\
\hline$E_{r}^{i}$ & $<40$ & $40 \sim 80$ & $80 \sim 160$ & $160 \sim 320$ & $>320$ \\
\hline$R I$ & $<150$ & $150 \sim 300$ & $300 \sim 600$ & $>600$ & \\
\hline
\end{tabular}

Table 7 Evaluation results of potential ecological hazard index of heavy metals

Specifically, $100 \%$ of the total potential ecological hazards are in the strong grade in these 11 reactor sites. $100 \%$ of the potential ecological hazards of $\mathrm{Hg}$ belongs to the strong level. The potential ecological harm of $100 \%$ of Cd belongs to the medium level, $80 \%$ of the As belongs to the strong level, and $20 \%$ of the As belongs to the medium level. In these 11 points of the sewage outfall, the total potential ecological hazard of $100 \%$ points belongs to strong grade. The potential ecological hazards of $100 \%$ of $\mathrm{Hg}$ belong to the strong level, the potential ecological hazards of $100 \%$ of $\mathrm{Cd}$ belong to the medium level, and the potential ecological hazards of 
other heavy metals belong to the lowest level. The potential ecological hazard index of all heavy metals in the office area is at the slight level. The overall potential ecological hazard level is slight and the potential harm to the human body is minimal.

\section{Conclusions}

(1) By sampling and detecting, the area is contaminated with heavy metals, mainly including $\mathrm{Hg}$ and As. At the reactor, 4 of the 5 sampling sites exceeds the standard of $\mathrm{Hg}, 5$ of As exceeds the standard. The highest concentration of $\mathrm{Hg}$ exceeds the standard 1.09 times and the highest concentration of As exceeds the standard 123.3 times.

(2) The evaluation results of Nemero pollution index show that the comprehensive soil pollution at the reactor belongs to the serious pollution level, the comprehensive soil pollution at the sewage outlet belongs to the light pollution $\sim$ medium pollution level, and the comprehensive soil pollution in the office area belongs to the still clean level. As pollution index in the soil at the reactor is much higher than that of the other five heavy metals, which belongs to severe pollution. $\mathrm{Hg}$ pollution slightly exceeds the standard value, belonging to light pollution. $\mathrm{Hg}$ and $\mathrm{As}$ in the soil should be repaired in the reactor and sewage outlet.

(3) The potential ecological risk assessment results show that the three heavy metals, such as $\mathrm{Ni}, \mathrm{Cu}$ and $\mathrm{Pb}$ in the three regions, are in the safe range. The total potential ecological harm of soil in reactor belongs to strong grade. The potential ecological harm of $\mathrm{Hg}$ is strong, the potential ecological harm of $\mathrm{Cd}$ belongs to the medium level, As of $80 \%$ points belongs to the strong level, and As of $20 \%$ points belongs to the middle level. The total potential ecological harm of soil at the sewage outlet belongs to strong grade, in which the potential ecological harm of $\mathrm{Hg}$ is strong, the potential ecological harm of $\mathrm{Cd}$ belongs to the medium level, and the other heavy metals are in the safe range. The total potential ecological hazard of soil in the office area is within the safe range.

\section{References}

1. G.H. Guo, F.C. Wu, F.Z. Xie, et al., J. of Environmental Sciences 24, 410 (2012)

2. T. Arao, S. Ishikawa, M. Murakami, et al., Paddy \& Water Environment 8, 247 (2010)

3. M.N. Rashed, J. of Hazardous Materials 178, 739 (2010)

4. Q.X. Zhou, Environmental Chemistry 25, 15 (2006)

5. Z.T. Yao, J.H. Li, H.H. Xie, et al. Procedia Environmental Sciences 16, 722 (2012)

6. G.T. Zhuang, J. of Chinese Academy of Science 30, 477 (2015)

7. S.X. Fan, Z.T. Gan, M.J. Li, et al., Chinese Agricultural Science Bulletin 26, 310 (2010)

8. X.B. Zeng, J.M. Xu, Q.Y. Hung, et al., Acta
Pedologica Sinica 50, 186 (2013)

9. Y. Ma, Y.M. Luo, Y. Teng, et al., Acta Pedologica Sinica 50, 196 (2013)

10. X.F. Liang, Y.M. Xu, L. Wang, et al., Acta Scientiae Circumstantiae 31, 1011 (2011)

11. Z.Y. Zhang, A. Jilili, F.Q. Jiang, Advances in Earth Science 29, 608 (2014)

12. M.F. Chen, L.Y. Luo, J. Song, et al., Administration \& Technique of Environmental Monitoring 23, 19 (2011)

13. L. Hakanson, Water Research 14, 975 (1980) 